\title{
The Impact of a Science Education Game on Students' Learning and Perception of Inhalants as Body Pollutants
}

\author{
Yvonne Klisch • Leslie M. Miller • Shu Wang • \\ Joel Epstein
}

Published online: 4 June 2011

(c) The Author(s) 2011. This article is published with open access at Springerlink.com

\begin{abstract}
This study investigated the knowledge gains and attitude shifts attributable to a unique online science education game, Uncommon Scents. The game was developed to teach middle school students about the biological consequences of exposure to toxic chemicals in an environmental science context, as well as the risks associated with abusing these chemicals as inhalants. Middle school students $(n=444)$ grades six through eight participated in the study consisting of a pre-test, three gameplay sessions, and a delayed post-test. After playing the game, students demonstrated significant gains in science content knowledge, with game usability ratings emerging as the strongest predictor of post-test content knowledge scores. The intervention also resulted in a shift to more negative attitudes toward inhalants, with the most negative shift occurring among eighth grade students and post-test knowledge gains as the strongest predictor of attitude change across all grade levels. These findings suggest that the environmental science approach used in Uncommon Scents is an efficacious strategy for delivering both basic science content and influencing perceived harm relating to the inhalation of toxic chemicals from common household products.
\end{abstract}

Y. Klisch · L. M. Miller $(\square)$

Center for Technology in Teaching and Learning, Rice

University, 6100 Main Street, MS 120, Houston, TX 77005, USA

e-mail: 1mm@rice.edu

S. Wang

Department of Psychology, Rice University, Houston, TX, USA

J. Epstein

Missouri Institute of Mental Health, St. Louis, MO, USA
Keywords Game-based learning - Science-based drug education - Environmental education - Toxic chemicals . Body pollution - Attitudes toward inhalants - Video game

\section{Introduction}

By middle school, students typically understand that drug abuse can have serious health consequences; what is missing is the how and why. The explanation of the biological effects of drugs in the body, however, requires an understanding of the normal functions of body systems. The underlying science used to explain these functions is encompassed in the National Science Content Standards (National Research Council 1996). For example, in the middle grades, Science Content Standard C relates the need for students to develop an "understanding of structure and function of living systems" and Standard F addresses developing an "understanding of personal health." Existing science-based drug education programs have been proven to be very effective in teaching relevant knowledge. For example, Brain Power! (Holtz and Twombly 2007) and The Doubles (Epstein et al. 2007), both funded by the National Institute on Drug Abuse, were successful in increasing students' knowledge about the biological effects of drugs in elementary and middle school populations.

The ongoing reduction of health classes from school curricula in many U.S. states, despite the mandate to address drug education in middle school, poses a real dilemma for educators (Kann et al. 2007). Many school districts are seeking ways to accomplish these dual goals, given a shrinking cadre of school-based health educators/ drug prevention specialists and the increasing demands of high stakes testing in science. How might the integration of 
drug education into the science curriculum be accomplished in a realistic and effective way?

The science education game Uncommon Scents was developed to teach science content aligned with state and national standards and to discourage adolescents from experimenting with inhalants. This study was designed to assess whether Uncommon Scents met these two different, yet complementary, goals.

\section{Background}

Inhalants as a Drug Education Topic

With a Science Education Drug Abuse Partnership Award from the National Institute on Drug Abuse, Uncommon Scents was developed to teach middle school students about the biological consequences of exposure to toxic chemicals and the risks associated with abusing these chemicals as inhalants. Uncommon Scents is part of a series of science education games dealing with substances of abuse (http://recon structors.rice.edu). Prior research demonstrated that the two previously developed games in this series increase middle school students' knowledge about the drugs and their harmful biological effects (Miller et al. 2002; Miller et al. 2006).

The urgency of addressing inhalants occurs for several reasons. Inhalant abuse is most common among younger adolescents whose knowledge about the adverse biological effects of the inhaled chemicals is minimal. In the 2009 Monitoring the Future survey, $8.1 \%$ of eighth graders stated that they have used inhalants at least once in the past year, compared to $6.1 \%$ of tenth graders and $3.4 \%$ of twelfth grader (Johnston et al. 2009). The preference of inhalant abuse among eighth graders is very different from any other drug abused by adolescents (Johnston et al. 2009; Wu and Ringwalt 2006; Neumark et al. 1998), possibly due to the fact that household products, such as glues, paints, and cleaners that can be subject to abuse may be found in almost any cleaning cabinet (Balster 1998; Balster et al. 2009). Even though some U.S. states have recently banned the use, possession, or distribution of inhalants to minors (Spigel 2009), for the most part, these products are cheap and legal to purchase and possess.

Additionally, the number of both eighth and tenth graders who think that people risk self-inflicted harm when they try inhalants is steadily declining, prompting researchers to describe this phenomenon as "generational forgetting." Similarly, although the disapproval rate for inhalant abuse is at $80 \%$ among eighth and tenth graders, it has gradually declined since the beginning of this decade (Johnston et al. 2009). The perceived harmlessness of inhalant abuse among many adolescents is in clear contrast to its severe health consequences. One of the acute effects of organic solvent inhalation is Sudden Sniffing Death, which results from cardiac arrest due to rapid release of adrenaline (Shepherd 1989; Bass 1970). Effects of nervous system damage caused by inhalants include muscle weakness, tremor, cortical atrophy, hearing loss, and cognitive impairment such as memory and attention deficits (Rosenberg et al. 2002; Brouette and Anton 2001; Williams and Storck 2007). Other health consequences include renal, lung and liver damage, bowel and bladder dysfunction, dermatitis, and reproductive toxicology (Brouette and Anton 2001; Jones and Balster 1998; Hannigan and Bowen 2010).

Inhalants as a Science Education Topic

The framework for integrating the information about inhalants into substantial science content in Uncommon Scents was a holistic environmental science approach based on an inhalant abuse curriculum developed by Isabel Burk, director of The Health Network (Adams and Morgan 2007). Rather than targeting inhalant abuse directly, Uncommon Scents focuses on the hazards of toxic chemicals in common household products and how to avoid exposure to these toxins. Presumably, framing the issue in this manner enables adolescents to recognize inhalants as toxins rather than drugs per se and to draw their own conclusions about the wisdom of using inhalants (Adams and Morgan 2007). The analogy to environmental pollution, endorsed by the National Inhalant Prevention Coalition (NIPC), holds a stronger science-based message approach than a "just say no" drug education message. Harvey Weiss, director of the NIPC, argues, "The only valid way to prevent inhalant abuse is through education and awareness that these aren't drugs, they're poisons and toxins" (quote in Fritz 2006). In addition, this approach also leverages the concerns many adolescents already have about air pollution and allows them to make the connection between air pollution caused by release of toxic chemicals and "body pollution" caused by inhaling these chemicals.

To allow teachers to tie Uncommon Scents with environmental lessons and with the circulatory or nervous system (topics which middle school teachers currently teach), the game includes examples of how breathing in toxic fumes, either purposely or accidentally, damages the body. Simultaneously, the learning objectives covered in the game are aligned to National Science Content Standards (National Research Council 1996) and the Benchmarks for Science Literacy (American Association for the Advancement of Science 1993) for middle school.

Instructional Design of Uncommon Scents

Uncommon Scents was produced through an iterative design process that engaged researchers, clinicians, 
educators, and students. In the game, the player enters a futuristic world in which he or she assumes the role of an agent for the Environmental Protection Agency in the fictional city of Neuropolis. The problem-based scenario charges the player with the urgent investigation of a hazardous chemical spill at a factory in Neuropolis. The narrative serves to set a motivational context (i.e., situates the learning), to allow students to inhabit a role in the game, and to provide structure to the scientific content, all contributing factors to the effectiveness of educational games (Squire 2006; Squire and Jan 2007; Barab et al. 2009; Brown et al. 1989; Dunleavy et al. 2009). In order to solve the case presented in the game, students need to gather information about the health effects of exposure to toxic chemicals. Thus, the game was intended to offer teachers a vehicle for student engagement and motivation, key parts of the learning cycle. The storyline is presented episodically, with each episode approximately 30 minutes in length. Episode One and Two end with a "cliff-hanger" intended to serve as an incentive for the player to continue to the problem's final solution.

During the game, the player visits different locations, communicates with virtual characters, and engages in virtual experiments, analyses, and interactive simulations (Table 1). In order to avoid cognitive overload and disorientation, which is often associated with purely exploratory learning models, the game uses guided discovery to promote constructive learning (Mayer 2004): while players have some freedom in their decision what to do next in the game, specific instructions keep them on the right path and hints on what to do next are available, though optional. Positive and negative feedback were built into each interactive segment. Players may "ask" the characters in the game for advice and suggestions by clicking on them. Quizzes were woven throughout the segments as checks for understanding to guard against the accretion of incorrect facts or assumptions. Figure 1 provides a screen capture illustrative of a check for understanding in the game.

Although the primary goal of Uncommon Scents was science-based drug education, we also expected that exposure to accurate knowledge about the dangers of inhaling toxic chemicals would result in more negative attitudes toward inhalants. An important strategy employed for achieving an attitudinal shift is the game's avoidance of direct and fear-based anti-inhalants messages, which have been proven to be less persuasive than non-threatening, indirect messages (Crano et al. 2007; Frey and Eagly 1993). Instead, players learn about inhalants in the context of investigating a chemical spill. The goal was to make adolescents appreciate the risks associated with accidental exposure to organic solvents, thus leading them to question

Table 1 Goals, activities, and intended conclusions from each episode of Uncommon Scents

\footnotetext{
Episode one

Goal Investigate a spill in a chemical plant that produces organic solvents.

Activities - Gather information about the health effects of exposure to organic solvents.

- Complete a safety training on how to avoid exposure to organic solvents.

- Correctly identify the spilled chemical as the organic solvent toluene.

- Connect the symptoms and presence of toluene in the blood in affected workers to the chemical exposure with epidemiologic testing.

Conclusion A worker had toluene in her blood and displayed symptoms typical for exposure to organic solvents, but was NOT exposed to the spill. She is identified as the "outlier".

Episode two

Goal Follow the case of the outlier.

Activities - Learn about hazardous household products, label warning signs, and how to use, store, and dispose of these products safely.

- Sort products based on their chemical composition.

- Perform tests for memory and selective attention that illustrate the effects of exposure to toxic paints and glues on brain functions.

Conclusion The outlier may have purposely inhaled toxic chemicals.

Episode three

Goal Gather scientific facts about the health consequences of inhaling toxic chemicals.

Activities - Analyze magnetic resonance images of the brain for effects of long-term inhalant abuse.

- Conduct an experiment to determine behavior of mice after exposure to toluene and learn about the important role of animal research.

- Perform an experiment that illustrates sudden sniffing death syndrome.

- Construct an informational website about the dangers of exposure to toxic chemicals in household products based on what has been learned.

Conclusion Exposure to organic solvents can cause brain atrophy and nervous system damage, as well as sudden death due to heart failure.
} 
Fig. 1 Screen shot of a check for understanding during a virtual experiment in Uncommon Scents. In the experiment, the player exposes mice to air (control group) or toluene (experimental group), respectively, and observes their burying behavior (LópezRubalcave et al. 2000)

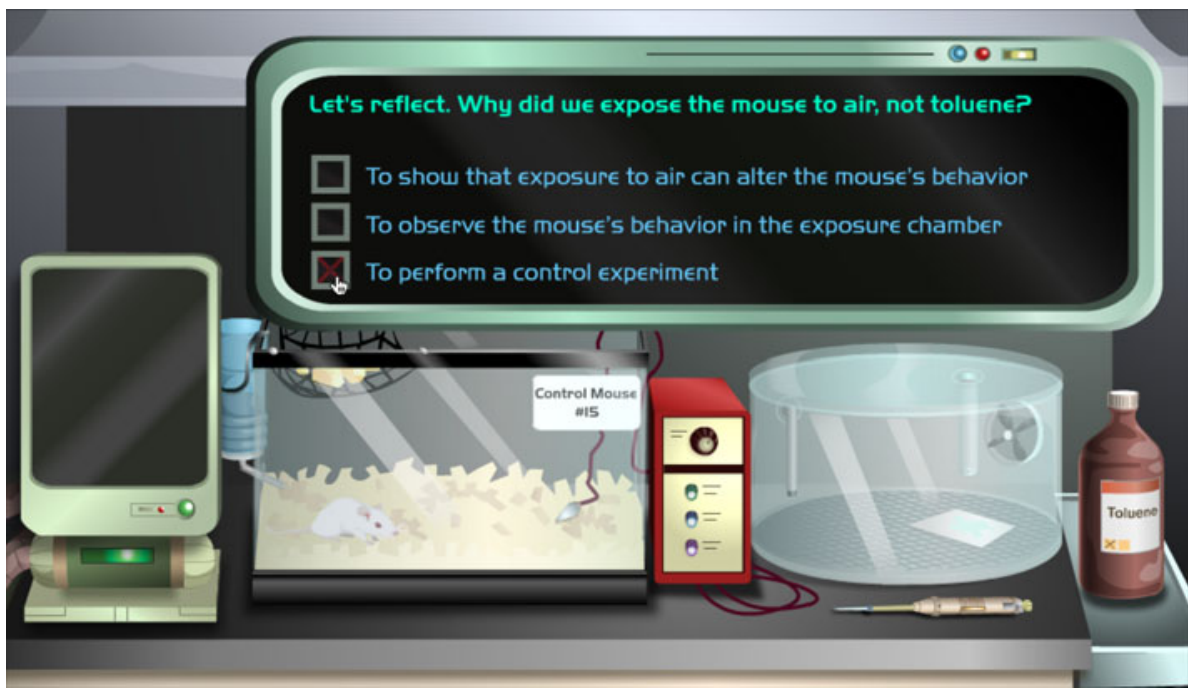

the judgment of purposely inhaling these toxic substances. Uncommon Scents was designed to provide a "stealth" prevention message in which scientific facts are presented to adolescents in an effort to change their attitudes (Holtz and Twombly 2007).

\section{Specific Research Questions}

1. Knowledge acquisition: will Uncommon Scents be effective in teaching middle school students about the biological effects of toxic chemicals in the environment?

2. Attitude change: compared to baseline, will students report more negative attitudes toward inhalants after playing Uncommon Scents?

\section{Research Design}

Participants

We sent an online solicitation to middle school science teachers who had volunteered at various professional development workshops and offered each teacher an incentive of $\$ 250$ for organizing the field test. The requirements for inclusion were: (1) endorsement from the school principal, (2) availability of at least 50 students from intact classes, (3) collection of parental and student informed consent, (4) guarantee of adequate computer access, and (5) assurance that teachers had not previously taught any of the content covered in Uncommon Scents to the group of students involved in the study.

The final sample included nine teachers' classes from seven public schools and two private schools in seven U.S. states and consisted of 444 students (47\% male) with 55 sixth graders, 276 seventh graders and 113 eighth graders. The student population represented $41.2 \%$ from urban areas, $39.4 \%$ from suburban areas and $19.4 \%$ from rural areas. Most respondents described themselves as Caucasian/White $(62.8 \%)$, followed by Hispanic/Latino (20.9\%) and African-American/Black $(6.1 \%)$. The remaining students reported their ethnicity as Asian/Pacific Islander (4.2\%), Native American (1.3\%), or other (4.7\%). In order to validate the representation of socio-economic status diversity in the sample, students were assigned to one of three economic groups as operationalized by free/reduced lunch percentages of the total school population. One of the schools was categorized as high disadvantage (more than $60 \%$ of students received free/reduced lunch), three schools as middle disadvantage (29-59\% of students received free/ reduced lunch), and five schools as low disadvantage (less than $29 \%$ of students received free/reduced lunch, including two private schools). The final sample contained $14.2 \%$ high disadvantage students $(n=63), 45.7 \%$ middle disadvantage students $(n=203)$, and $40.1 \%$ low disadvantage students $(n=178)$.

\section{Procedure}

All students who provided parental consent participated in 5 sessions, each lasting approximately $45 \mathrm{~min}$, in the schools' computer labs. During Session One, students were presented with a brief assent form that explained the research and the purpose of the study, giving them a second option to decline participation. In a subsequent screen, students were asked for some basic demographic information (e.g., grade, gender) and an identification number that had been assigned to them by their teachers. The subsequent screens included the pre-test of content 
knowledge and an assessment of attitudes toward inhalants. During Sessions Two, Three, and Four students played the first, second, and third episode of Uncommon Scents, respectively. Requirements for these sessions were that (1) Session Two was scheduled with a minimum delay of three days after Session One (the longest delay was five days), and (2) the sessions were administered on three different days spread over the course of a maximum of two weeks (the longest spread was ten days). Session Five was scheduled with a minimum delay of three days after finishing Session Four (the longest delay was seven days) to test if students retained the content knowledge and included assessment of satisfaction, game usability, the identical assessment of attitudes toward inhalants used in Session One, and the post-test of content knowledge. Again, students were asked for their identification numbers to facilitate matching of pre- and post-test results while assuring their anonymity. Teachers were instructed to avoid preteaching the content and to refrain from providing a review of content until after the field test concluded.

\section{Measures}

Content knowledge. The content knowledge scale consisted of 30 items that reflected basic information accessible to the player within Uncommon Scents. The test items were developed based on consensus advice from teachers and the results of an informal content knowledge assessment performed with 56 seventh grade students different from the participants of the field test. All items were presented as multiple-choice questions with four response options. The majority of the questions (12 of 30) asked about health effects of exposure to toxic chemicals (e.g., "What happens to toxic chemicals in the body after inhaling?" Answer: They are absorbed into the bloodstream. Other content areas included the nervous system, the nature of organic solvents, and hazardous household products (e.g., "How can household products pollute the air?" Answer: They can give off toxic vapors). The internal consistency reliability (Cronbach's $\alpha$ ) was .61 for the content knowledge pre-test and .86 for the post-test.

Attitudes. The attitude questions included three scales: satisfaction, game usability, and attitudes toward inhalants. For each scale, participants read statements and rated their level of agreement on a five-point Likert-scale from $1=$ "strongly disagree" to $5=$ "strongly agree." The attitudes toward inhalants scale was developed on the basis of the General Attitudes Towards Drug Use measure (Epstein et al. 2007) and consisted of ten items (e.g., "There is really nothing wrong with using inhalants."). The scale was coded so that $1=$ most negative and $5=$ most positive attitude toward inhalants. Some items, however, were reverse coded (e.g., "Using inhalants is risky for your health."). The internal consistency reliability (Cronbach's $\alpha$ ) for this scale was .85 for the pre-test and .88 for the posttest.

The satisfaction scale has been used and validated in previous studies of similarly formatted games. It contained three items to assess how well participants liked the game (e.g., "If there were more games like this, I would play them."). A game usability scale consisting of three items was developed to assess how students rated the game in terms of game play difficulty (e.g., "It was easy to find out what to do next while playing the game."). Internal consistency reliabilities (Cronbach's $\alpha$ ) were .83 for satisfaction and .59 for game usability.

\section{Results}

Of the original sample of 610 middle school students who consented and completed the pre-test, the data from 167 were excluded from analyses because of duplication of identification numbers $(n=14)$, or because students did not complete the study, either because they missed one or more of the three episodes of the game $(n=47)$, or because they missed the post-test $(n=105)$. Teachers confirmed that the typical reason for non-completion was absenteeism and that none of the students in the original sample opted out or declined participation. The final sample included 444 students.

\section{Acquisition of Content Knowledge}

The group mean for content knowledge test scores increased from 13.60 (SD 4.05; $45.3 \%$ correct) before playing Uncommon Scents to 17.63 (SD 6.53; 58.8\% correct) after playing the game (Table 2). The comparison of delayed post-test performance with pre-test performance on content knowledge using a paired sample $t$-test revealed that this increase was significant $(t(443)=17.53, p<.01)$ with a large effect size (Cohen's $d=1.33$; Cohen 1988).

\section{Changes in Attitudes Toward Inhalants}

Comparison of pre-test and post-test attitude scores revealed that students' attitudes toward inhalants changed to the negative (pre-test mean 1.79, SD 0.60; post-test mean 1.65, SD 0.625) after playing Uncommon Scents (Table 2). A paired sample $t$ test revealed that this attitude shift was significant, although the magnitude of the change was relatively small $(t(443)=5.47, p<.01$; Cohen's $d=.37)$. 
Table 2 Test scores (mean, SD) and correlations between study variables (1-6.). Reliabilities (Cronbach's $\alpha$ ) on the diagonal

\begin{tabular}{|c|c|c|c|c|c|c|c|c|}
\hline & Mean & SD & 1. & 2. & 3. & 4. & 5. & 6. \\
\hline 1. Pre-test content knowledge & 13.60 & 4.05 & $(.61)$ & & & & & \\
\hline 2. Post-test content knowledge & 17.63 & 6.53 & $.674 * *$ & $(.86)$ & & & & \\
\hline 3. Pre-test inhalants attitudes & 1.79 & 0.60 & $.307 * *$ & $.306 * *$ & $(.85)$ & & & \\
\hline 4. Post-test inhalants attitudes & 1.65 & 0.625 & $.347 * *$ & $.474 * *$ & $.585^{* *}$ & $(.88)$ & & \\
\hline 5. Satisfaction & 3.75 & 0.85 & .073 & $.148 * *$ & $.222 * *$ & $.216^{* *}$ & $(.83)$ & \\
\hline 6. Game usability & 3.60 & 0.71 & $.141 * *$ & $.247 * *$ & $.169 * *$ & $.206 * *$ & $.462 * *$ & $(.59)$ \\
\hline
\end{tabular}

$* * p<.01 ; n=444$

Satisfaction and Game Usability

Group means were 3.75 (SD 0.85) for satisfaction with the game and 3.60 (SD 0.71) for game usability (Table 2).

\section{Differences Between Genders}

To analyze whether knowledge gains differed between genders, a repeated measures ANOVA was conducted using the General Linear Model (GLM). Pre-test content knowledge and post-test content knowledge were entered as two repeated measurement occasions and gender was entered as a between-subject variable. The analysis suggested a difference between genders at the $p<.05$ level $(F(1,442)=4.56, p=.03)$. The group means revealed that knowledge gains were slightly higher among female students (pre-test mean 13.57, SD 4.06; post-test mean 18.05 , SD $6.21 ; n=237$ ) compared to male students (pretest mean 13.65, SD 4.04; post-test mean 17.15, SD 6.86; $n=207)$.

Another GLM analysis was done with pre-test and posttest inhalant attitudes entered as two repeated measurement occasions and gender entered as a between-subject variable. There was no evidence of interaction between gender and attitudes toward inhalants $(F(1,442)=2.01, p=.16)$. An independent sample $t$-test with female and male students revealed that neither satisfaction nor game usability ratings differed between genders (satisfaction: $t(442)=$ $-.22, p=.83$; game usability: $t(442)=-.33, p=.74)$. Taken together, although female students benefited slightly more from the game than male students with regard to content learning, there was no difference between genders in the magnitude of the change of attitudes toward inhalants as well as satisfaction and usability ratings.

\section{Differences Across Grades}

To investigate possible differences in knowledge gains across grades, a GLM analysis was conducted with pre-test and post-test content knowledge entered as two repeated measurement occasions and grades entered as a between- subject variable. Because eighth graders are the demographic with the highest usage of inhalants (Johnston et al. 2009), we focused on this age group and combined sixth and seventh graders. There was no difference across grades in content knowledge acquisition $(F \quad(1,442)=.63$, $p=.43)$. When pre-test and post-test inhalants attitudes were entered as two repeated measurement occasions and grades were entered as a between-subject variable in a different GLM analysis, a significant interaction between grade and attitude change was observed $(F(1,442)=$ 19.92, $p<.001)$. As seen in Fig. 2 , the biggest change in attitudes toward inhalants occurred in eighth graders (pretest mean 1.88, SD 0.57; post-test mean 1.54, SD 0.54), whereas the attitude change in the combined group of grades six and seven was of a smaller magnitude (pre-test mean 1.76, SD 0.61; post-test mean 1.69, SD 0.65). An independent sample $t$-test with eighth graders and combined sixth and seventh graders revealed that neither satisfaction nor game usability ratings differed between grades (satisfaction: $t(442)=.62, p=.54$; game usability:

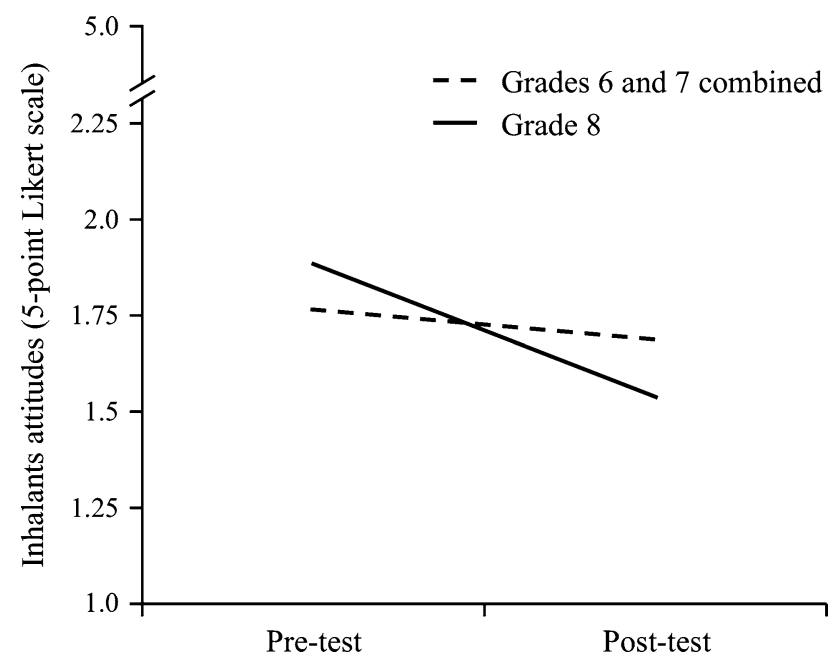

Fig. 2 Interaction between attitudes toward inhalants and grade. $1=$ most negative and $5=$ most positive attitude toward inhalants. Grades six and seven combined pre-test: mean 1.76 (SD 0.61), posttest: mean 1.69 (SD 0.65). Grade eight pre-test: mean 1.88 (SD 0.57), post-test: mean 1.54 (SD 0.54) 
Table 3 Predicting post-test content knowledge scores controlling for pre-test content knowledge

\begin{tabular}{lll}
\hline Predictor & $\Delta \mathrm{R}^{2}$ & $\beta$ \\
\hline Step 1 & $.45^{* *}$ & \\
Pre-test content knowledge & & $.67^{* *}$ \\
Step 2 & $.03^{* *}$ & \\
Pre-test content knowledge & & $.65^{* *}$ \\
Satisfaction & & .04 \\
Game usability & & $.14^{* *}$ \\
Total $\mathrm{R}^{2}$ & $.48^{* *}$ & \\
\hline
\end{tabular}

$* * p<.01 ; n=444$

$t(442)=-.37, p=.71)$. Thus, although students in the two groups evidenced similar content knowledge gains and satisfaction and game usability ratings, the game had a bigger effect on eighth graders than on students in lower grades with regard to changing attitudes toward inhalants.

Predictors of Content Knowledge Acquisition and Change of Attitudes Toward Inhalants

As shown in Table 2, scores on pre-test and post-test content knowledge were correlated with each other, and they both significantly correlated with the pre-test and the post-test attitudes toward inhalants. Satisfaction with the game and game usability were also significantly correlated with post-test content knowledge and post-test attitudes toward inhalants.

Given the correlations among the variables, the independent contribution of the potential predictors was examined by conducting a hierarchical multiple linear regression (Table 3). In the hierarchical multiple regression model, post-test content knowledge was entered as the criterion variable, and pre-test content knowledge was entered in the first step to control for prior knowledge and to examine how much of the remaining variance could be accounted for by the potential predictors (satisfaction and game usability). In the second step, satisfaction and game usability ratings were entered. This analysis revealed that after controlling for pre-test content knowledge, perceptions of game usability accounted for significant incremental variance in post-test knowledge scores $(\beta=.14$, total $\left.R^{2}=.48, p<.01\right)$, whereas satisfaction with the game had no influence. The results suggest that the easier a player found the game mechanics, the more likely he/she learned from it.

To address the question whether knowledge related to inhalants can change attitudes toward inhalants, a second regression analysis examined the predictors of attitude change toward inhalants (Table 4). Post-test attitudes toward inhalants were entered as the dependent variable; pre-test attitudes and pre-test content knowledge were
Table 4 Predicting post-test attitudes toward inhalants controlling for pre-test content knowledge and pre-test attitudes

\begin{tabular}{lcc}
\hline Predictor & $\Delta \mathrm{R}^{2}$ & $\beta$ \\
\hline Step 1 & $.37^{* *}$ & $.53^{* *}$ \\
Pre-test inhalants attitudes & & $-.19^{* *}$ \\
Pre-test content knowledge & & \\
Step 2 & $.07^{* *}$ & $.49^{* *}$ \\
Pre-test inhalants attitudes & & .04 \\
Pre-test content knowledge & & $-.35^{* *}$ \\
Post-test content knowledge & & \\
Total $\mathrm{R}^{2}$ & $.44^{* *}$ & \\
\hline
\end{tabular}

$* * p<.01 ; \mathrm{N}=444$

entered in the first step as the controlled-for variables. Posttest content knowledge was entered in the second step. After controlling for pre-test attitudes toward inhalants and pre-test content knowledge, performance on the content knowledge post-test was a strong predictor of post-test attitudes toward inhalants $\left(\beta=-.35\right.$, total $R^{2}=.44$, $p<.01)$, demonstrating that the more students learned from Uncommon Scents, the more their attitudes toward inhalants shifted to the negative.

\section{Discussion}

The reported results indicate that Uncommon Scents was successful in improving adolescents' science content knowledge. The concern that the gain scores reflect only an average of $58.8 \%$ on the post-test can be mediated by several factors. First, the total intervention exposure was less than three hours. Second, testing the power of the game in the absence of any classroom reinforcement created a somewhat artificial situation. It could be argued that under normal science classroom conditions, teachers would provide guided inquiry, hands-on activities, and follow-up discussion, thus boosting the learning gains. Additionally, the finding of no interaction between grade and content knowledge acquisition reaffirms that the game is well targeted to students across all middle school grades.

The finding that female students learned slightly more from the game than male students is surprising because in previous studies both genders benefited equally from science-based digital games (Joiner et al. 2010; Epstein et al. 2007). A more detailed assessment of factors that might have contributed to the gender differences, such as the game's understandability and credibility, would be important for the development of future educational games that are equally effective among both genders.

Not surprising was the finding that pre-test knowledge was the main contributing factor to post-test knowledge gains. After controlling for pre-test knowledge, the 
usability of the game was found to be the only factor that accounted for variance in post-test content knowledge scores. Students who reported less difficulty with the game play may have expended less cognitive effort on deciphering the game mechanism and more cognitive effort on the game content, resulting in higher content knowledge gains. One concern is that the internal reliability of the game usability scale was relatively low, which might be attributable to the fact that the scale only had three items. However, it can be expected that if the scale were more reliable, the contribution of game usability to explain the variance in content knowledge gains would be even larger. Future research is needed to refine the game usability scale.

Overall, the usability of the game was rated slightly above average. Thus, increasing the ease of game play might improve student learning as long as the game is challenging enough to keep students engaged and excited. Satisfaction with the game, however, was not found to have any significant influence on post-test content knowledge scores, indicating that students learned from the game regardless of their satisfaction. Even though the game had the desired outcome in terms of content knowledge gain, a satisfaction rating that is only slightly above average leaves room for improvement. Increased beta testing and a more detailed assessment of student satisfaction would be important aspects in an effort to increase the enjoyment of the game.

The second aspect of the study focused on changes in adolescents' attitudes toward inhalants. After playing the game, students reported significantly more negative attitudes toward inhalants than before the intervention. Although the magnitude of the change was relatively small, it is encouraging considering the short exposure to the intervention and the fact that students' attitudes toward inhalants were already somewhat negative at baselinethus, there was simply very little room for movement toward more negativity about inhalants.

While gender was not correlated with the observed attitude shift, the analysis of grade differences revealed that the attitude change of students in eighth grade was of a larger magnitude compared to students in the lower grades. Eighth graders displayed more positive attitudes toward inhalants at baseline than younger students, which is reflective of other studies indicating that eighth graders represent the demographic with the highest prevalence for inhalant abuse and the lowest disapproval rate of inhalants when compared to older adolescents (Johnston et al. 2009). More importantly, students in eighth grade displayed more negative inhalants attitudes after playing the game compared to younger students. Thus, although the overall attitude change toward inhalants observed in this study was small, the results suggest that a stronger attitude shift might occur among adolescents who have more favorable attitudes toward inhalants before the intervention.
The final regression analysis revealed that post-test content knowledge was a strong predictor of post-test attitudes toward inhalants, demonstrating a direct relationship between learning facts about toxic chemicals and developing more negative attitudes toward the abuse of these chemicals. While the specific goal of the Uncommon Scents intervention for use in science classrooms is clearly knowledge gain, the attitude shifts might be viewed as encouraging precursors of inhalant avoidance. A more longitudinal study that includes intentional and behavioral measures could help to see if the attitude shift translates into changes in adolescents' intentions to use inhalants and actual inhalant abuse.

A limitation of this study is the lack of a control condition. A comparison of students who played Uncommon Scents to students who either did not receive any intervention or who played a different, unrelated game would allow a stronger argument about the efficacy of the intervention. Additionally, the high rate of student dropouts between pre-test and post-test might decrease the level at which generalization is possible. A more detailed analysis of the 152 students who either missed one or more of the three episodes of the game or missed the post-test revealed that there were no differences in demographics between completers and non-completers. However, the non-completers did have slightly lower content knowledge scores and more positive attitudes toward inhalants at baseline (mean content knowledge 12.20, SD 4.11, $t(594)=3.70, p<.01$; mean inhalants attitudes 20.44 , SD $6.20, t(594)=-4.41$, $p<.01)$. Because teachers reported that the missing data were caused by general absenteeism, it would be difficult to develop strategies to avoid student dropouts in the future. Arguably, students who are more likely to be absent may perhaps be those who are most at risk, and may therefore have benefitted the most from the game. It is possible that without the restrictions of the experimental protocol, these students could have realized similar shifts.

In conclusion, Uncommon Scents was effective in increasing adolescents' knowledge about the science content presented in the game. Furthermore, the increased knowledge resulted in a shift to more negative attitudes toward inhalants, indicating that the game was successful in enabling adolescents to identify inhalants as body pollutants. Further studies of Uncommon Scents, used in combination with more traditional drug prevention approaches, may amplify this intervention. Meanwhile, Uncommon Scents makes it possible to engage science educators in drug education.

Acknowledgments This study was supported by a Science Education Drug Abuse Partnership Award (R25 DA 021810) from the National Institute on Drug Abuse, National Institutes of Health. Any opinions, findings, conclusions or recommendations expressed in this material are those of the authors and do not necessarily reflect the 
views of the National Institute on Drug Abuse. We would like to acknowledge Dr. Cathrine Sasek at the National Institute on Drug Abuse for her support of science education and to thank the many teachers and students who participated in the field test.

Open Access This article is distributed under the terms of the Creative Commons Attribution Noncommercial License which permits any noncommercial use, distribution, and reproduction in any medium, provided the original author(s) and source are credited.

\section{References}

Adams S Morgan ML (2007) Inhalant abuse prevention: staff education and student curriculum. Richmond, Virginia, Commonwealth of Virginia department of education. http://healthnet work.org. Accessed 30 September 2010

American Association for the Advancement of Science (1993) Benchmarks for science literacy. Oxford Press, New York

Balster RL (1998) Neural basis of inhalant abuse. Drug Alcohol Depend 51(1-2):207-214

Balster RL, Cruz SL, Howard MO et al (2009) Classification of abused inhalants. Addiction 104(6):878-882

Barab SA, Scott B, Siyahhan S, Goldstone R, Ingram-Goble A et al (2009) Transformational play as a curricular scaffold: using videogames to support science education. J Sci Edu Technol $18(4): 305-320$

Bass M (1970) Sudden sniffing death. J Am Med Assoc 212(12):2075-2079

Brouette T, Anton R (2001) Clinical review of inhalants. Am J Addict 10(1):79-94

Brown JS, Collins A, Duguid S (1989) Situated cognition and the culture of learning. Edu Res 18(1):32-42

Cohen J (1988) Statistical power analysis for the behavioral sciences, 2nd ed edn. Erlbaum, Hillsdale

Council NationalResearch (1996) National science education standards. National Academy Press, Washington

Crano WD, Siegel JT, Alvaro EM et al (2007) Overcoming adolescents' resistance to anti-inhalant appeals. Psychol Addict Bahaviors 21(4):516-524

Dunleavy M, Dede C, Mitchell R (2009) Affordances and limitations of immersive participatory augmented reality simulations for teaching and learning. J Sci Edu Technol 18(1):7-22

Epstein J, Collins KK, Thomson NR et al (2007) The doubles: evaluation of a substance abuse education curriculum for elementary school students. J Child Adolesc Subst Abus 16(4):1-22

Frey KP, Eagly AH (1993) Vividness can undermine the persuasiveness of messages. J Pers Soc Psychol 65(1):32-44

Fritz GK (ed) (2006) Treating inhalant abuse by prevention and raising parental awareness. The Brown university child and adolescent behavior letter. vol. 22. Wiley, San Francisco
Hannigan JH, Bowen SE (2010) Reproductive toxicology and teratology of abused toluene. Syst Biol Reprod Med 56(2):184-200

Holtz KD, Twombly EC (2007) A preliminary evaluation of the effects of a science education curriculum on changes in knowledge of drugs in youth. J Drug Education 37(3):317-333

Johnston LD, O'Malley PM, Bachman JG et al (2009) Monitoring the future national results on adolescent drug use: overview of key findings. National Institute on Drug Abuse, Bethesda

Joiner R, Iacovides J, Owen M, et al. (2010) Digital games, gender and learning in engineering: do females benefit as much as males? J Sci Edu Technol doi:10.1007/s10956-010-9244-5

Jones HE, Balster RL (1998) Inhalant abuse in pregnancy. Obstet gynecol clin N Am 25(1):153-167

Kann L, Telljohann SK, Wooley SF (2007) Health education: results from the school health policies and programs study 2006. J Sch Heal 77(8):408-434

López-Rubalcave C, Hen R, Cruz SL (2000) Anxiolytic-like actions of toluene in the burying behavior and plus-maze test: differences in sensitivity between $5-\mathrm{HT}_{1 \mathrm{~B}}$ knockout and wild-type mice. Behav Brain Res 115(1):85-94

Mayer RE (2004) Should there be a three-strikes rule against pure discovery learning? the case for guided methods of instruction. Am Psychol 59(1):14-19

Miller LM, Schweingruber H, Oliver R et al (2002) Teaching neuroscience through web adventures: adolescents reconstruct the history and science of opioids. Neuroscientist 8(1):16-22

Miller L, Moreno J, Willcockson I (2006) An online, interactive approach to teaching neuroscience to adolescents. CBE-Life Sci Edu 5(2):137-143

Neumark Y, Delva J, Anthony JC (1998) The epidemiology of adolescent inhalant involvement. Arch Pediatr Adolesc Med 152(8):781-786

Rosenberg NL, Grigsby J, Dreisbach J et al (2002) Neuropsychologic impairment and MRI abnormalities associated with chronic solvent abuse. Clin Toxicol 40(1):21-34

Shepherd RT (1989) Mechanism of sudden death associated with volatile substance abuse. Hum Toxicol 8:287-291

Spigel S (2009) State laws on inhalant use. http://www.cga.ct.gov/ 2009/rpt/2009-R-0251.htm. Accessed 27 January 2011

Squire KD (2006) From content to context: videogames as designed experiences. Edu Res 35(8):19-29

Squire KD, Jan M (2007) Mad city mystery: developing scientific argumentation skills with a place-based augmented reality game on handheld computers. J Sci Edu Technol 16(1):5-29

Williams JF, Storck M, American Academy of Pediatrics Committee on Substance Abuse et al (2007) Inhalant abuse. Pediatrics 119(5):1009-1017

Wu LT, Ringwalt CL (2006) Inhalant use and disorders among adults in the United States. Drug Alcohol Depend 85(1):1-11 